ARCHIVO ESPAÑOL DE ARTE, XCII, 368

OCTUBRE-DICIEMBRE 2019, pp. 427-434

ISSN: 0004-0428, eISSN: 1988-8511

https://doi.org/10.3989/aearte.2019.27

\title{
VARIA
}

\section{APORTACIONES A LA BIOGRAFÍA ARTÍSTICA DEL CORÓGRAFO ANTONIO MANCELLI: SU PRODUCCIÓN AMERICANA}

\author{
Pablo Cisneros Álvarez ${ }^{1}$ \\ Universidad Internacional de la Rioja
}

\begin{abstract}
El presente artículo da a conocer dos documentos del Archivo General de Indias que aportan datos a la biografía y producción artística de Mancelli.

Palabras clave: Mancelli; Siglo XVII; Cartografía urbana; planos; mapas americanos.

\section{CONTRIBUTION TO THE ARTISTIC BIOGRAPHY OF THE CHOROGRAPHER ANTONIO MANCELLI: HIS AMERICAN PRODUCTION}

\begin{abstract}
This article presents two documents from the Archivo General de Indias that contribute data to the biography and artistic production of Mancelli.

Key words: Mancelli; $17^{\text {th }}$ century; urban cartography; urban plans; American maps.

Cómo citar este artículo / Citation: Cisneros Álvarez, Pablo (2019): “Aportaciones a la biografía artística del corógrafo Antonio Mancelli: su producción americana”. En: Archivo Español de Arte, vol. 92, núm. 367, Madrid, pp. 427-434. https://doi.org/10.3989/aearte.2019.27.
\end{abstract}

Del corógrafo italiano Antonio Mancelli están documentados sus periodos peninsulares en la ciudad de Valencia ${ }^{2}$ - donde tuvo como valedor a Jerónimo Sirvent quien le pondría en contacto con el Marqués de Caracena -33 y, después, en la villa y corte de Madrid. Poco se sabe de su formación en su país de procedencia. De su producción en España se conocen el plano de Valencia (1608) ${ }^{4}$ [fig. 1], la realización de uno de Madrid (ca. 1622) —-todavía por descubrir — 5 y otro de la plaza Mayor de la villa $(c a .1623)^{6}$ [fig. 2] — de ambos hay constancia en colecciones

1 pablo.cisneros@unir.net / ORCID iD: http://orcid.org/0000-0002-4875-9273

2 Benito, 1992: 29-38. Cisneros, 2012: 309-454. Ramírez, 2017: 165-176.

3 AA.VV., 1997: 40-45. Anselmi, 2004: 79. Bérchez/Gómez-Ferrer, 2004: 109; 2006: 21-22. Gil, 2018: 133-153. Tormo, 1977.

${ }^{4}$ Arévalo, 2003: 211. Benito, 1992: 29-38. Cisneros, 2012: 309-454. Faus, 2011: 90-92. Llopis/Perdigón, 2010 : 64-65. Ramírez, 2017: 165-176. Rosselló, 2004: 164; 2009: 253-257. Roselló/Chapapría, 2000: 24-30

5 Arévalo, 2003: 211-213. Barbeito, 2013: 107-122. Escobar, 2007:62-71; 2014: 53-54. Matilla, 1980: 103-107. Molina, 1960. Muñoz de la Nava, 2000: 149-165; 2005: 45-83; 2006: 165-219; 2007: 127-181; 2007b: 141-190. Pereda, 1998: 103-134. Pérez, 1981. Sanz, 1997a: 435-467; 1997b: 3-11.

${ }^{6}$ Escobar, 2005: 33-38; 2007: 32-62, 66-67; 2014: 53-55. 

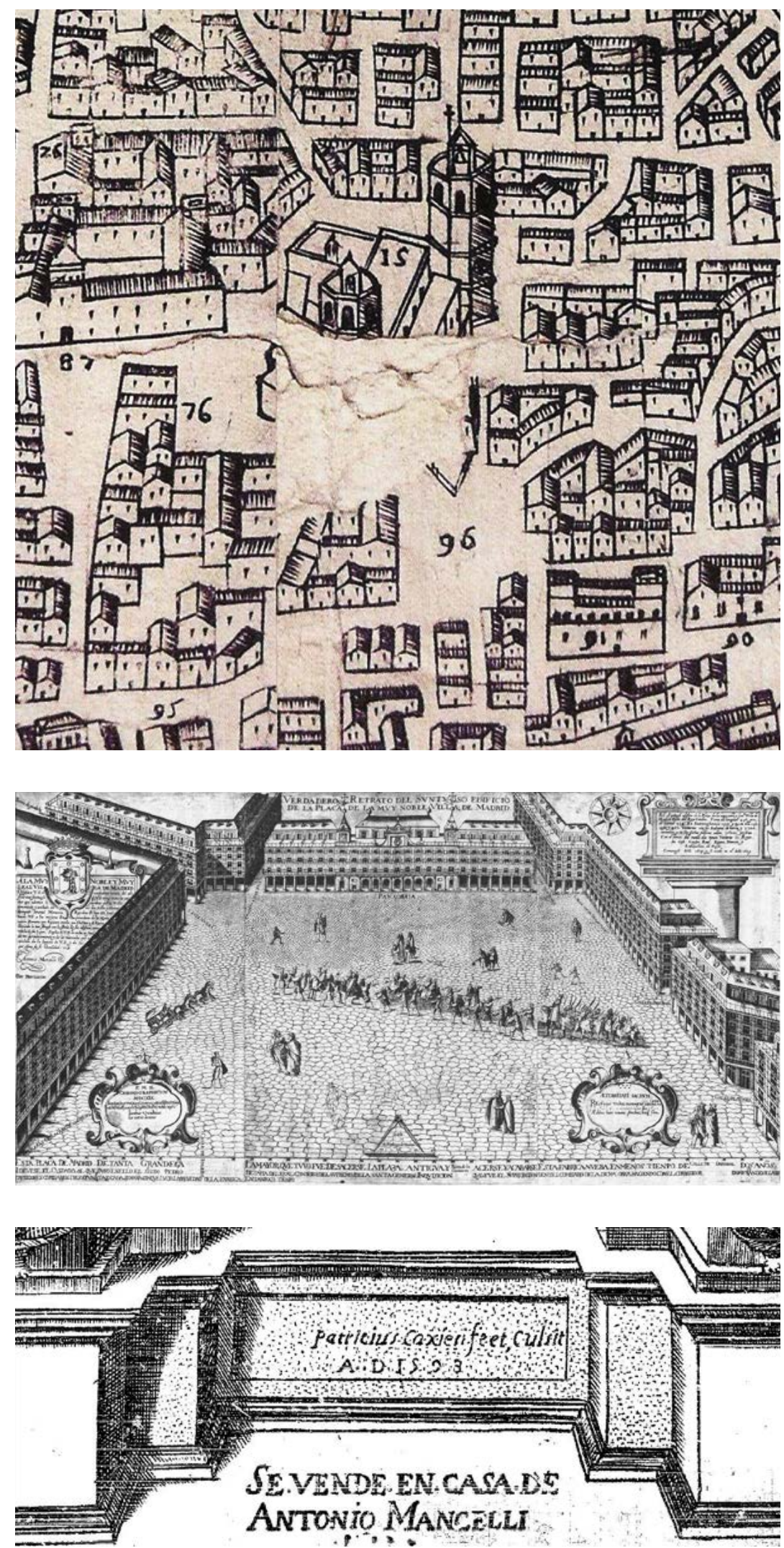

Fig. 1. Detalle del plano de Valencia de Mancelli (1608). Museo Municipal, Ayuntamiento de Valencia.

Fig. 2. Plano de la Plaza Mayor de Madrid, de Antonio Mancelli. British Library (Londres).

Fig. 3. Detalle de la portada de Reglas de los cinco órdenes de arquitectura de Vignola. Impreso en Madrid [después de 1619] y que se vendía en casa de Antonio Mancelli. Biblioteca Nacional de España (Madrid). 
particulares contemporáneas - ${ }^{7}$. Quizás pudo realizar alguna pintura de la Plaza Mayor de Madrid $^{8}$. Igualmente, hay documentación que constata sus trabajos como librero ${ }^{9}$ [fig. 3], editor ${ }^{10}$, perito de bienes ${ }^{11}$ o fiador ${ }^{12}$. La última noticia que se tiene de Mancelli es la realización en 1643 del mapa Descripción del Principado de Cataluña de Joseph Pellicer de Tovar ${ }^{13}$. Mancelli tuvo que morir cerca de 1643, pues no se conocen trabajos posteriores a este. Suponiendo que nace en torno a $1575^{14}$, y que llegó a Valencia sobre los veinticinco años, falleció, por tanto, con alrededor de 65 años. Como pedía en su testamento, tuvo que ser sepultado en Madrid en la iglesia del convento de San Francisco, en la capilla de los Terceros, a cuya Orden pertenecía ${ }^{15}$.

\section{La producción cartográfica americana de Antonio Mancelli}

Nuevas noticias de Mancelli se han encontrado en el Archivo General de Indias. En él hay dos cartas de pago que constatan que Mancelli realizó mapas también de ciudades hispanoamericanas. Esto amplía el trabajo del italiano fuera de la península, con lo que no debería de descartarse un viaje de Mancelli al nuevo continente. Sin embargo, no figura en la documentación del Archivo General de Indias que Mancelli viajase a las Américas. Es muy posible que Mancelli realizara los planos que se citan en la documentación sin dejar la península. Atendiendo a los contactos que tuvo con arquitectos, cronistas y científicos de la corte, Mancelli pudo acceder a los mapas americanos realizados previamente por otros geógrafos que sí que viajaron a América. De hecho, esto fue una práctica algo habitual. Contemporáneamente, Pedro Texeira firmó su plano del Estrecho de Magallanes (realizado en 1919 y publicado en Madrid en 1621) inspirándose en documentos anteriores de cartógrafos que sí que fueron a Sudamérica ${ }^{16}$.

La metodología seguida por Mancelli en sus obras estaba apoyada por un escrupuloso trabajo de campo en el cual mantenía un contacto directo con las ciudades que representaba. Esta sistemática de trabajo se vería quizás empañada por el mapa Descripción del Principado de Cataluña. Sin embargo, éste fue como se sabe un plagio de Pellicer de Tovar del mapa de Ortelius y Mancelli se encargó de su impresión, no de su realización. Por tanto, Mancelli, pudo viajar a Hispanoamérica, al igual que hicieron otros muchos artistas urbanos en la Edad Moderna ${ }^{17}$. Si realmente emprendió este viaje, al estar fechados estos documentos en 1633 y 1634, como se verá, Mancelli debería de tener por esas fechas unos 55 años. Además, hay que recordar que Mancelli ya había testado en 1632 y que, como indica en su testamento, su estado de salud probablemente no era por entonces el más adecuado para viajar a las Américas. Él mismo declaró que estaba "enfermo en la cama de enfermedad corporal y en mi buen juicio y entendimiento natural"18. No obstante, hay que plantearse que el italiano pudo testar precisamente ese año de 1632 por estar pensando en un próximo viaje, algo que era muy frecuente teniendo en cuenta las dificultades que entrañaba viajar en el siglo XVII.

La primera de las cartas de pago conservadas en el Archivo General de Indias está fechada el 20 de junio de 1633. A continuación se transcribe íntegro el documento que lleva por título [al margen] Libramiento de 40 reales a Antonio Manceli que se le restan, debiendo de unas molduras e iluminación que hizo de la Isla Española. Corregido. Dice así:

\footnotetext{
7 Agulló, 1997: 29-30.

8 Escobar, 2003: 104-105; 2005: 34-35; 2007: 101.

9 Matilla, 1982: 202.

10 Vignola, 1619a; 1619b. Bustamante/Marías, 1985: 39-40. Rodríguez, 1985: 11-43.

11 AHPM: protocolo 2589, ff. 211v-213. Matilla, 1982: 199.

12 AHPM: protocolo 6444, ff. 991r-v. Matilla, 1982: 199.

13 Hernando, 1998: 38-39.

14 Marías, 2001: 101. Pereda/Marías, 2002: 379, nota 46.

15 AHPM: protocolo 3607, ff. 1220v-1221. Muñoz de la Nava, 2006: 206-207.

16 Pereda/Marías, 2002: 12.

17 Kagan, 1998: 125-169.

18 AHPM: protocolo 3607, f. 1220. Muñoz de la Nava, 2005: 206.
} 


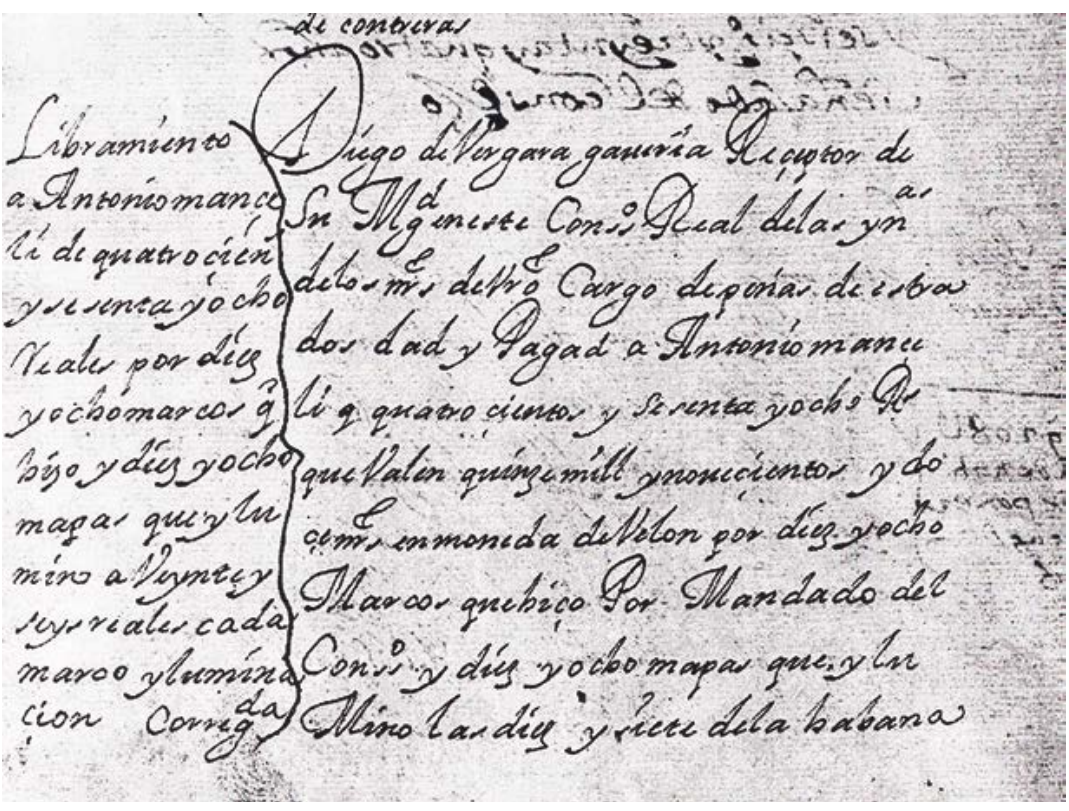

Fig. 4. Detalle del documento original "Libramiento a Antonio Manceli de cuatrocientos sesenta [...]" (AGI: Indiferente, 434, L. 6/1/702. f. 346v). Archivo General de Indias (Sevilla).

Diego de Vergara Gaviria, receptor de su Magestad en este Consejo de los mares, que vienen en vuestro poder o a él viniesen de poner aplicados a gastos de extractos, dad y pagad a Antonio Manceli cuarenta reales que valen mil y trescientos y sesenta maravedíes en vellón, que se le restan debido de unas molduras [e] iluminación que hizo de la Isla Española. Y tomad su carta de pago, lo de que en su poder hubiere, con lo cual y este libramiento, habiendo tomado la razón de él los contadores de cuentas de su Majestad [que] residen en este Consejo, mandamos se os reciban y pasen en cuenta sin otro recaudo alguno, lo cual amplío sin embargo de la orden que se os está dada por auto de seis de noviembre del año pasado del seiscientos y treinta y dos, en que se aplicaron a los de estrados para otros efectos del servicio del Consejo. Firmado en Madrid a veinte de Junio de mil y seiscientos y treinta y tres años $[\ldots]^{19}$.

Este primer documento deja claro que se le restaban, o daban a cuenta cuarenta reales por la "iluminación" que realizó de la isla La Española al igual que por unas molduras, se supone que de esta obra. Este último trabajo es algo con lo que Mancelli ya estaba familiarizado pues, en la documentación referente al plano de Madrid, el ayuntamiento de la villa le encargó tareas similares ${ }^{20}$. Aunque no se especifica, es bastante factible que el mismo Consejo sea el cliente de este plano. No se indica el destinatario de la obra, si bien es muy probable, tal y como era lo habitual, que fuese para alguna persona que ostentase un alto cargo. Por último, tampoco consta la tirada de los ejemplares.

El otro documento encontrado en el Archivo General de Indias es igualmente significativo. Está fechado el 15 de septiembre de 1634. Es otra carta de pago referente a 18 mapas que iluminó. La fuente deja muy claro que es Mancelli quien ilumina los 18 mapas. El documento precisa que son 17 mapas de La Habana - la ambigüedad del documento no permite saber si son 17 ejemplares de un único mapa o 17 diferentes - y otro de la isla La Española así como también sus respectivas molduras. Por tanto, habría que entender que éste hace referencia a unos encargos diferentes de los precedentes. Sin embargo, no se tiene que descartar que el mapa de la isla de Santo Domingo que se cita perteneciese a la misma plancha que refiere el documento anterior. Si fuese así, evidentemente el Consejo de Indias, que aquí sí que figura como cliente, quedó

19 Archivo General de Indias (en adelante AGI): Indiferente, 434, L. 6/1/123, f. 57.

${ }^{20}$ Pérez, 1891: III, 159. 
satisfecho con el primer trabajo del italiano y, como consecuencia, hubiese decidido repetir el mapa de la isla de La Española e, igualmente, continuar ofreciendo trabajo a Mancelli mediante el compromiso de realizar otros 17 mapas de La Habana.

Este segundo documento lleva por título [al margen] Libramiento a Antonio Manceli de cuatrocientos sesenta y ocho reales por diez y ocho marcos que hizo y diez y ocho mapas que iluminó a veinte y seis reales cada marco, iluminación corregida [fig. 4]. A continuación se transcribe íntegro:

Diego de Vergara Gaviria, receptor de su Magestad en este Consejo Real de las Indias de los mares, de vuestro cargo de perias/pesias [i?] de cobrados, dad y pagad a Antonio Manceli cuatrocientos y sesenta y ocho reales que valen quince mil novecientos y doce maravedíes en moneda de vellón, por diez y ocho marcos que hizo por mandado del Consejo y diez y ocho mapas que iluminó, las diez y siete de La Habana y la otra de la Isla Española, a razón de veinte y seis reales cada uno. Y tomada su carta de pago, con la cual y este libramiento de que an de tomar la razón los contadores de cuentas de su Magestad que residen en este Consejo, mandamos se os reciban y pasen en cuenta sin otro recaudo alguno. Firmado en Madrid a quinze de Septiembre de mil y seiscientos y treinta y cuatro años señalado del Consejo ${ }^{21}$.

Evidentemente, tanto el primer documento como el segundo, se refieren a cartas de pago, con lo que Mancelli tuvo que realizar satisfactoriamente todo lo que se expone en ellos. Es muy difícil conocer qué pudo ser de estos mapas o cuál puede ser el paradero actual ${ }^{22}$. Desde el siglo XVI, el Consejo de Indias consideró la cosmografía como un secreto de estado ${ }^{23}$. Pronto, esta institución empezó a generar una sensibilidad para descubrir el Nuevo Mundo desde el punto de vista histórico, geográfico, etnográfico o natural. Sabedores de toda esta información, se buscó su protección y salvaguarda para que todo este conocimiento no cayera en manos de los enemigos, los cuales ansiaban cambiar la hegemonía de España en aspectos políticos y espirituales en tierras americanas ${ }^{24}$.

La monarquía española de los Habsburgo empezó a ser consciente de que si los enemigos no conocían el territorio y sus rutas no podían planificar las estrategias bélicas para perpetrar los ataques. La protección de la información cartográfica se hizo atendiendo a diferentes procedimientos. Desde Carlos V, los Habsburgo buscaron que las obras cartográficas fueran de monopolio real, supervisadas por las autoridades de la corona. El monarca encargó a sus virreyes o gobernantes mapas, cuadros o descripciones de los territorios peninsulares y del Nuevo Mundo ${ }^{25}$. Esto posibilitó que los proyectos cartográficos fueran de mayores dimensiones. Pero, no obstante, sería complicado realizar trabajos de relevancia sin el apoyo de la corona ${ }^{26}$. Otra forma que tuvo la corona de salvaguardar los documentos cartográficos fue el trámite, bien vigilado, que se impuso a la hora de consultarlos, hecho este que el Consejo de Indias se encargaba de supervisar ${ }^{27}$.

Francisco de Holanda, al hilo de lo anterior, expuso a Miguel Ángel: “¿qué fineza puede ningún bravo caballero entonces hacer mayor que mostrar delante de los ojos de los bisoños y desacostumbrados soldados la hechura de la ciudad que han de combatir antes que la combatan?"28. El conocimiento cartográfico, sin duda, era un saber que era mejor tenerlo guar-

21 AGI: Indiferente, 434, L. 6/1/702. ff. 346v-347r.

22 Se ha consultado el portal de Archivos Españoles en Red (PARES) en busca de los mapas citados en los documentos. Al Archivo General de Indias se fue personalmente. Igualmente, se ha puesto empeño en la consulta de los fondos del Archivo General de Simancas, donde se sabe que el Consejo General de Indias enviaba copias de los documentos cartográficos que encargaba (Portuondo, 2009: 104). No se ha encontrado ningún documento que se pueda relacionar con los mapas de Mancelli citados en la documentación.

23 Portuondo, 2009: 103-109.

24 Portuondo, 2009: 103.

25 Fiorani, 2005. Parker, 1992: 124-152. Pereda, 2007: 161-182. Sanz, 2000: 289-305. Woodward, 2007.

26 Kagan, 2002: 60.

27 Portuondo, 2009: 104.

28 Francisco de Holanda, 1921: 181. 
dado $^{29}$. La monarquía demandaba estas representaciones para su recaudo. Meridianas son las palabras del trabajo en Pontevedra del alférez Pedro Rodríguez quien en 1595 "sacó los planos della para enviar a Vuestra Magestad y por ser tan ymportante a su rreal servicio y tan opuesta a los corsarios y ladrones y llabe de toda esta tierra [...]"30. Más ayuda a entender la función que pudieron tener los mapas realizados por Mancelli unas palabras de Carducho escritas en la misma fecha que el primero de los documentos presentados "[...] no se enterará por este medio del sitio y forma de una ciudad, de un castillo fuerte, de un seno y baía del mar, y de los montes, cosa importante a las Monarquías, no sólo para adornar las galerías y Palacios Reales con semejantes pinturas, sino también en casos arduos, para que sirva a la defensa de nuestros Reinos y ofensa de los estraños" ${ }^{31}$. Es evidente que, en el siglo XVII, los monarcas hispanos llevaron a cabo una férrea política de sigilo, celosos de su poder y conscientes del valor que tenía para sus adversarios la información sobre sus posesiones territoriales ${ }^{32}$. Sin duda, los planos americanos de Mancelli, a día de hoy, continúan con ese sigilo.

Con esto, es probable que los ejemplares de los mapas de Mancelli citados en los dos documentos fueran custodiados cuidadosamente por el Consejo de Indias o por altos cargos administrativos, a quienes se les solían regalar ejemplares. En este sentido, habrá que esperar a que salgan a la luz, si es que se conservan, los mapas indianos realizados por Mancelli.

Junto a la importancia de los datos que aparecen, es muy reseñable el nuevo ámbito en el que supuestamente desempeñó su actividad. Si esto fue así, se podrían ampliar a tres los lugares en los que el corógrafo italiano trabajó. Así, habría que considerar una primera etapa de formación que probablemente se desarrollaría en Italia, un segundo ámbito de producción que sería el de la península ibérica con dos ciudades especialmente significativas en su carrera como lo fueron respectivamente Valencia y Madrid y, por último, el hispanoamericano, destino al que pudo viajar para realizar los encargos que recoge la documentación presentada.

\section{BIBLIOGRAFÍA}

AA.VV. (1997): La expulsión de los moriscos del Reino de Valencia. Valencia: Bancaixa.

Agulló, Mercedes (1994): Documentos para la historia de la pintura española. I. Madrid: Museo del Prado.

Anselmi, Alessandra (2004): Il diario del viaggio in Spagna del cardinele Francesco Barberini scritto da Cassiano dal Pozzo. Madrid: Fundación Carolina/Ediciones Doce Calles.

Arévalo, Federico (2003): La representación de la ciudad en el Renacimiento. Levantamiento urbano y territorial. Barcelona: Fundación Caja de Arquitectos.

Barbeito, José Manuel (2013): “Juan Gómez de Mora, Antonio Mancelli y Cassiano del Pozzo”. En: Archivo Español de Arte, LXXXVI, 342, Madrid, pp. 107-122.

Benito, Fernando (1992): “Un plano axonométrico de Valencia diseñado por Manceli el 1608”. En Ars Longa, 3, Valencia, pp. 29-38.

Bérchez, Joaquín/Gómez-Ferrer, Mercedes (2004): "Mirar y pintar la ciudad. Notas sobre la Valencia al viu en el siglo XVII". En: AA.VV.: Historia de la ciudad. III. Arquitectura y transformación urbana de la Valencia. Valencia: $\mathrm{COACV} /$ Ayuntamiento de Valencia/Universitat de València, pp. 102-115.

Bérchez, Joaquín/Gómez-Ferrer, Mercedes (2006): "Mirar y sentir la ciudad. La Valencia al viu en el siglo XVII”. En: De la Peña, Concepción (coord.): En torno al Barroco. Miradas múltiples. Murcia: Universidad de Murcia, pp. 13-27.

Bustamante, Agustín/Marías, Fernando (1985): “Apuntes arquitectónicos madrileños hacia 1660”. En: Archivo Español de Arte, LVIII, 34-43.

Cámara, Alicia (2009): "Retratos urbanos para la guerra". En: Rodríguez, Víctor/Rodríguez, Inmaculada/ Zuriaga, Vicent: El sueño de Eneas. Imágenes utópicas de la ciudad. Castellón/Valencia: UJI/ Biblioteca Valenciana, pp. 65-88.

Carducho, Vicente (1633) (ed. Calvo, Francisco, 1979): Diálogos de la pintura, su defensa, origen, esencia, definición, modos y diferencias. Madrid, Turner.

Cisneros, Pablo (2012): La imagen grabada de la ciudad de Valencia entre 1499 y 1695. Tesis doctoral. Valencia: Universitat de València.

\footnotetext{
29 Hernando, 2013: 179-240.

30 Cámara, 2009: 74.

31 Carducho: 1633: 453.

32 Hernando: 2002: 80
} 
Escobar, Jesús (2003): The Plaza Mayor and the Shaping of Baroque Madrid. Cambridge: Cambridge University Press.

Escobar, Jesús R. (2005): “Antonio Manzelli. An early View of Madrid (c. 1623) in The British Library”. En: Anuario del Departamento de Historia y Teoría del Arte, XVII, Madrid, pp. 33-38.

Escobar, Jesús (2007): La Plaza Mayor y los orígenes del Madrid del Barroco. Donostia-San Sebastián: Nerea.

Escobar, Jesús R. (2007): "Map as Tapestry: Science and Art in Pedro Teixeira's 1656 Representation of Madrid". En: The Art Bulletin, 96, 1, Londres, pp. 50-69.

Faus, Alfredo (2011): "Equívocos, mentiras, ocultaciones y medias verdades en la historia de la cartografía impresa valenciana (1584-1797)". En: Cuadernos de Geografia, 89, Valencia, pp. 71-98.

Fiorani, Francesca. (2005): The marvel of maps: Art, cartography and politics in Renaissance Italy. New Haven: Yale University Press.

Gil, Yolanda (2018): "La tapicería de la expulsión de los moriscos. Un proyecto frustrado de Rodrigo Calderón”. En: Locus Emoenus, 16, Barcelona, pp. 133-153.

Francisco de Holanda (1921) (ed. Tormo, Elias): De la pintura antigua. Madrid: Real Academia de Bellas Artes de San Fernando.

Hernando, Agustín (1998): Contemplar un territorio. Los mapas de España en el Theatrum de Ortelius. [Madrid]: Centro Nacional de Información Geográfica.

Hernando, Agustín (2002): "Poder, cartografía y política de sigilo en la España del siglo XVII". En: Pereda, Felipe/Marías, Fernando (eds.): El Atlas del Rey Planeta. La descripción de España y de las costas y puertos de sus reinos de Pedro Texeira. Madrid: Nerea, pp. 72-97.

Hernando, Carlos José (2013): “UUna corte sin rey? Imagen virreinal y saber ceremonial en Nápoles”. En: Cabeza, Antonio/Carrasco, Adolfo (coords.) Saber y gobierno. Ideas y práctica del poder en la Monarquía de España (Siglo XVII). Madrid: Actas Editorial, pp. 179-240.

Kagan, Richard L. (con la colaboración de Marías, Fernando) (1998): Imágenes urbanas del mundo hispánico: 14931780. Madrid: El Viso.

Kagan, Richard L. (2002): “Arcana imperii: Mapas, ciencia y poder en la corte de Felipe IV”. En: Pereda, Felipe/Marías, Fernando (eds.): El Atlas del Rey Planeta. La descripción de España y de las costas y puertos de sus reinos de Pedro Texeira. Madrid: Nerea, pp. 49-70.

Llopis, Amando/Perdigón, Luis (2010): Cartografia histórica 1608-1944. Valencia: Universidad Politécnica de Valencia.

Matilla, Antonio (1980): "Autor y fecha del plano más antiguo de Madrid. La incógnita resuelta". En: Anales del Instituto de Estudios Madrileños, XVII, Madrid, pp. 103-107.

Molina, Miguel (1960): Planos de Madrid de los siglos XVII y XVIII. Madrid: Instituto de Estudios de Administración Local.

Muñoz de la Nava, José Miguel (2000): "El Prado de San Jerónimo, el plano de Antonio Marceli y la música”. En: Torre de los Lujanes, 42, Madrid, pp. 149-165.

Muñoz de la Nava, José Miguel (2005): “Antonio Mancelli: corógrafo, iluminador, pintor y mercader de libros en el Madrid de Cervantes (I)”. En: Torre de los Lujanes, 57, Madrid, pp. 45-83.

Muñoz de la Nava, José Miguel (2006): "Antonio Mancelli: corógrafo, iluminador, pintor y mercader de libros en el Madrid de Cervantes (II)". En: Torre de los Lujanes, 58, Madrid, pp.165-219.

Muñoz de la Nava, José Miguel (2007): "La suntuosa Plaza Mayor de Madrid, Corte de los Reyes Católicos de España, que representó Antonio Mancelli (I)". En: Torre de los Lujanes, 60, Madrid, pp. 127-181.

Muñoz de la Nava, José Miguel (2007b): "La suntuosa Plaza Mayor de Madrid, Corte de los Reyes Católicos de España, que representó Antonio Mancelli (II)". En: Torre de los Lujanes, 61, Madrid, pp. 141-190.

Parker, Geoffrey (1992): "Maps and minister. The spaninsh Habsburg”. En: Buisseret, David (ed.): Monarch, minister and maps. The emergence of cartography as a tool of goberment in Early Modern Europe. Chicago: University of Chicago Press, pp. 124-152.

Pereda, Felipe (1998): "Iconografía de una capital barroca: Madrid entre el simbolismo y la ciencia". En: Espacio, Tiempo y Forma, 11, serie VII, Madrid, pp. 103-134.

Pereda, Felipe (2007): "En la era de la imagen del mundo: cartografía y policía en la monarquía católica". En: Cuaderno de la Fundación Marcelino Botín. Cuaderno observatorio de tendencias. El mundo de los mapas., 7, Santander, pp. 161-182.

Pérez, Cristóbal (1981): Bibliografía madrileña. Madrid: Tipografía de los Huérfanos.

Ramírez, Germán (2017): "El plano de València de Antonio Manceli (1608): noticias, vicisitudes y aclaraciones de un documento excepcional, pero no único". En: Pasiones Bibliográficas II. Valencia: Societat Bibliogràfica Valenciana Jerònima Galés, pp. 165-176.

Rodríguez, Alfonso (1985): "La Regla de J. Barozzi de Vignola y su difusión en España”. En: Vignola, Jacopo: Regla de los Cinco Órdenes de Arquitectura. Madrid: Albatros, pp. 11-43.

Rosselló, Vicenç M./Esteban, Julià (2000): La fachada septentrional de la ciudad de Valencia. Valencia: Bancaja.

Rosselló, Vicenç M. (2004): “Tomás Vicente Tosca y su entorno ilustrado. Obra autógrafa y atribuciones”. En: Eria, 6465, Oviedo, pp. 159-176.

Rosselló, Vicenç M. (2008): Cartografia Històrica dels Països Catalans. València: Publicacions de la Universitat de València i Institut d'Estudis Catalans.

Sanz, José María (1997a): "La guadianesca historia del primer plano madrileño, hecho en 1622, cuando San Isidro sube a los altares”. En: Anales del Instituto de Estudios Madrileños, XXXVII, Madrid, pp. 435-467. 
Sanz, José María (1997b): “Año mil seiscientos veintidós. ¿Fue un milagro de San Isidro, darle a Madrid un plano?”. En: Topografia y Cartografia, XIV, 78, enero-febrero, Madrid, pp. 3-11.

Sanz, José María (2000): "Las representaciones geográficas y corográficas como elementos de prestigio y representación de la monarquía: el mapa de España y las descripciones de ciudades de Enrique Cock”. En: Martínez, Enrique: Actas del Congreso Madrid, Felipe II y las ciudades de la monarquía. Madrid: Editorial Actas, vol. 2, pp. 289-305.

Tormo, Juan (1977): "Siete grandes lienzos de la expulsión de los moriscos valencianos". En: Valencia Atracción, 105, febrero, Valencia, pp. 8 y ss.

Vignola (1619a): Regla de los cinco órdenes de architectura de Jacome de Vignola. Agora de nuevo traduzido de toscano en romance por Patricio Caxés i florentino, pintor y criado de su majestad. Madrid: Vicente Carducho.

Vignola [posterior a 1619b]: Regla de los cinco órdenes de architectura de Jacome de Vignola. Agora de nuevo traduzido de toscano en romance por Patricio Caxés i florentino, pintor y criado de su magestad. En: Madrid: [Antonio Mancelli].

Woodward, David (ed.) (2007): Cartography in the European Renaissance. Chicago \& London: University of Chicago Press.

Fecha de recepción: 12-IV-2018

Fecha de aceptación: 10-I-2019 